\title{
01.1
}

\section{Моделирование условий охлаждения германата висмута $\mathrm{Bi}_{2} \mathrm{GeO}_{5}$}

\author{
(C) Т.В. Бермешев ${ }^{1}$, В.П. Жереб ${ }^{1,2}$, И.Ю. Губанов ${ }^{1}$, А.Б. Набиулинн ${ }^{3}$, В.П. Ченцов ${ }^{4}$, В.В. Рябов ${ }^{4}$, \\ А.С. Ясинский ${ }^{1,5}$, Н.В. Мердак ${ }^{1}$, О.В. Юшкова ${ }^{1}$, М.П. Бундин ${ }^{1}$, В.М. Беспалов ${ }^{1}$, \\ Е.В. Мазурова ${ }^{6}$, Д.С. Ворошилов ${ }^{1}$, Е.Ю. Подшибякина ${ }^{1}$ \\ ${ }^{1}$ Сибирский фредеральный университет, Красноярск, Россия \\ ${ }^{2}$ Сибирский университет науки и технологий им. акад. М.Ф. Решетнева, Красноярск, Россия \\ ${ }^{3} \mathrm{OОО} \mathrm{„Красноярский} \mathrm{котельный} \mathrm{завод“,} \mathrm{Красноярск,} \mathrm{Россия}$ \\ ${ }^{4}$ Институт металлургии УрО РАН, Екатеринбург, Россия \\ ${ }_{6}^{5}$ IME, Institute for Process Metallurgy and Metal Recycling, RWTH Aachen University, Aachen, Germany \\ ${ }^{6}$ Институт химии и химической технологии СО РАН, Красноярск, Россия \\ E-mail: irbis btv@mail.ru
}

Поступило в Редакцию 5 апреля 2021 г.

В окончательной редакции 30 апреля 2021 r.

Принято к публикации 30 апреля 2021 г.

Показана возможность моделирования процессов охлаждения метастабильного соединения $\mathrm{Bi}_{2} \mathrm{GeO}_{5}$ при помощи программного комплекса ProCAST. Несмотря на ряд допущений, использованных при моделировании, результаты расчетов показали хорошую сходимость с реальными скоростями охлаждения расплавов и могут быть полезны для развития моделирования в системе $\mathrm{Bi}_{2} \mathrm{O}_{3}-\mathrm{GeO}_{2}$ с целью получения метастабильных материалов с заданным комплексом свойств и характером микроструктуры.

Ключевые слова: германат висмута, метастабильное соединение, моделирование, время охлаждения, кристаллизация.

DOI: 10.21883/PJTF.2021.15.51230.18803

Метастабильный германат висмута $\left(\mathrm{Bi}_{2} \mathrm{GeO}_{5}\right)$ со слоистой кристаллической структурой типа Ауривиллиуса, образующийся при кристаллизации переохлажденного расплава, является сегнетоэлектриком с высокой температурой Кюри, обладает высокой ионной проводимостью по кислороду, а также уникальными каталитическими свойствами. Он вызывает большой интерес для водородной энергетики и экологии благодаря своим фотокаталитическим свойствам в оптическом диапазоне излучений, в том числе для дезактивации токсичных органических соединений и оксидов азота (NO), а также в качестве катализатора для окислительной димеризации метана. Данное соединение также используется для синтеза перспективных стеклокерамических материалов.

Система $\mathrm{Bi}_{2} \mathrm{O}_{3}-\mathrm{GeO}_{2}$ представлена стабильной диаграммой состояния и двумя метастабильными. В [1-4] по результатам исследований область жидкого состояния на фазовой диаграмме системы $\mathrm{Bi}_{2} \mathrm{O}_{3}-\mathrm{GeO}_{2}$ была разделена на три температурные зоны: $A, B$ и $C$, охлаждение расплава от которых (от температур начала охлаждения $t_{\text {st.cool. }}$ ) по-разному влияет на состояние образующихся кристаллических фаз. Существование температурных зон и влияние условий охлаждения расплава на фазовый состав образующихся кристаллических фаз экспериментально подтверждены в $[5,6]$.

Способы получения $\mathrm{Bi}_{2} \mathrm{GeO}_{5}$ (гидротермальный синтез, метод осаждения, закалка с отжигом, твердофазный синтез, золь-гель и др.) хотя и имеют вполне определенные достоинства и преимущества, но все же в большинстве своем представляют собой довольно трудо- емкие и длительные по времени процессы, требующие значительных затрат, дополнительного оборудования и компонентов реакции. В работе [6] нам удалось надежно показать, что способ синтеза из расплава данных слоистых соединений не только возможен, но и максимально прост и удобен в исполнении при простой термической обработке расплава. При этом для его осуществления требуются лишь исходные компоненты $\left(\mathrm{Bi}_{2} \mathrm{O}_{3}, \mathrm{GeO}_{2}\right)$, тигель и печь.

С учетом того факта, что синтез метастабильного германата висмута $\mathrm{Bi}_{2} \mathrm{GeO}_{5}$ из расплава является одним из самых быстрых и простых способов получения этого перспективного материала, встает вопрос о возможности моделирования процессов нагрева и охлаждения с целью получения данного соединения с заранее заданным комплексом свойств и характером микроструктуры.

Таким образом, цель настоящей работы состоит в систематизации известных теплофизических характеристик и попытке моделирования условий охлаждения метастабильного соединения $\mathrm{Bi}_{2} \mathrm{GeO}_{5}$ с помощью программного комплекса ProCAST, а также оценке полученных результатов с помощью сравнения их с результатами, полученными экспериментальным путем.

Плотность материала измерялась при комнатной температуре с помощью аналитических автоматических весов „Vibra HT“ методом гидростатического взвешивания и далее принималась за константу вплоть до температуры солидуса. Значение плотности расплава при температуре $1297^{\circ} \mathrm{C}$ было взято из работы [7] и 

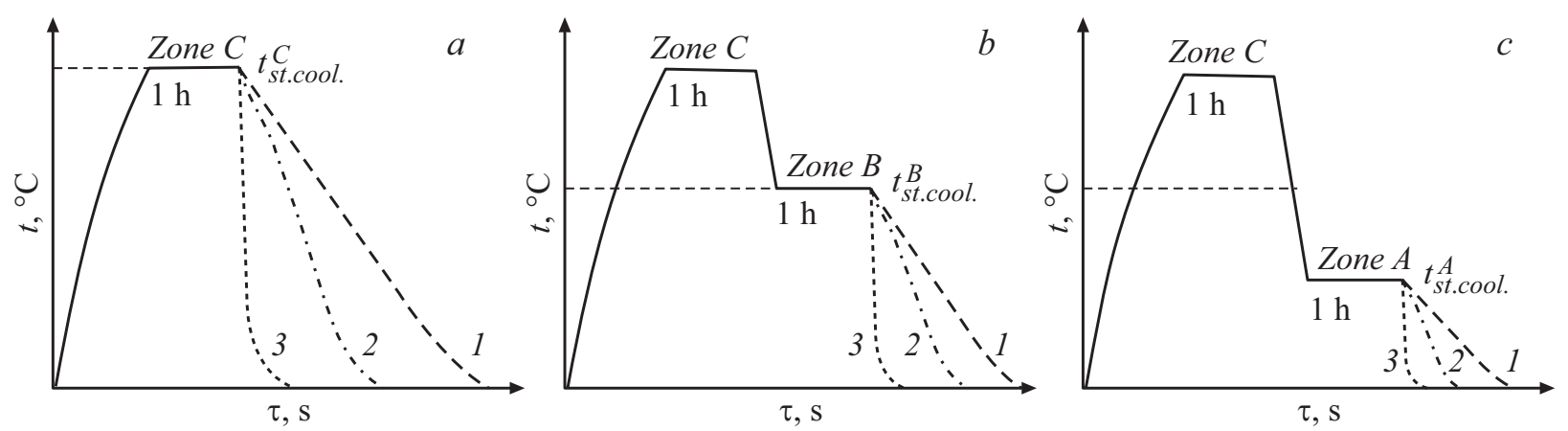

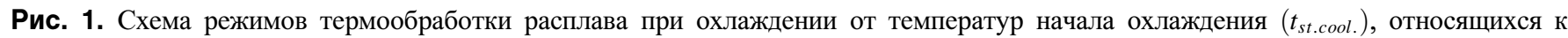
различным температурным зонам: $C(a), B(b)$ и $A(c) .1$ - охлаждение с печью, 2 - охлаждение на воздухе, 3 - охлаждение тигля в воде.

Таблица 1. Значения теплофизических характеристик $\mathrm{Bi}_{2} \mathrm{GeO}_{5}$ в зависимости от температуры

\begin{tabular}{c|c||r|c}
\hline$t,{ }^{\circ} \mathrm{C}$ & $C_{p}, \mathrm{~J} /(\mathrm{mol} \cdot \mathrm{K})$ & $t,{ }^{\circ} \mathrm{C}$ & $\rho, \mathrm{g} / \mathrm{cm}^{3}$ \\
\hline 82 & $174[8]$ & 20 & 7.4817 \\
127 & $179[8]$ & 1297 & $7.66[7]$ \\
\cline { 3 - 4 } 227.1 & $188[8]$ & $t,{ }^{\circ} \mathrm{C}$ & $\lambda, \mathrm{W} /(\mathrm{m} \cdot \mathrm{K})$ \\
\cline { 3 - 4 } 327 & $195[8]$ & 299 & 1.02 \\
427.1 & $201[8]$ & 400 & 0.95 \\
527 & $206[8]$ & 500 & 1.07 \\
627.1 & $211[8]$ & 600 & 1.35 \\
727 & $217[8]$ & 700 & 1.89 \\
$\mathbf{8 2 7}$ & $\mathbf{2 2 4}$ & 1067 & $0.20[9]$ \\
$\mathbf{9 2 7}$ & $\mathbf{2 3 0}$ & & \\
$\mathbf{1 0 2 7}$ & $\mathbf{2 3 7}$ & & \\
$\mathbf{1 1 2 7}$ & $\mathbf{2 4 3}$ & & \\
$\mathbf{1 2 2 7}$ & $\mathbf{2 4 9}$ & &
\end{tabular}

также принималось за константу вплоть до температуры ликвидуса.

Для расчетов температуры ликвидуса и солидуса брались согласно диаграммам метастабильного равновесия. В зависимости от температуры начала охлаждения они составили 837 и $820^{\circ} \mathrm{C}$ для зоны $C$ и $879^{\circ} \mathrm{C}$ для зоны $B$.

С учетом сохранения метастабильного состояния расплава после его термической обработки [6] для расчетов охлаждения расплава из зоны $A$ принимались значения ликвидуса и солидуса не стабильной диаграммы состояния, а метастабильной, полученной охлаждением из зоны $B$.

Аналогичные допущения были приняты и для коэффициента теплопроводности.

Значения теплоемкости при температуре в диапазоне $82-727^{\circ} \mathrm{C}$ были взяты из работы [8] и методом математического прогнозирования (расчет по уравнению (1), описывающему линейную аппроксимацию, где $x-$ температура нагрева) продолжены до температуры $1227^{\circ} \mathrm{C}$ :

$$
y=0.0629 x+172.1 \text {. }
$$

Измерение коэффициента температуропроводности проводилось на установке LFA 457 MicroFlash (компания Netzsch). Расчет коэффициента теплопроводности (ג) осуществлялся по формуле

$$
\lambda=\alpha C_{p} \rho,
$$

где $\alpha-$ коэффициент температуропроводности, $C_{p}-$ теплоемкость материала, $\rho$ - плотность материала.

Плотность рассчитывалась по формуле

$$
\rho=m / v
$$

где $m$ - масса образца, $v$ - объем образца. Пористость материала в расчет не принималась.

Насколько нам известно, исследований теплопроводности расплава состава метастабильного соединения $\mathrm{Bi}_{2} \mathrm{GeO}_{5}\left(1: 1 \mathrm{Bi}_{2} \mathrm{O}_{3}-\mathrm{GeO}_{2}\right)$ ранее не проводилось, и в литературе таких данных найти не удалось. Поэтому в качестве значения теплопроводности расплава для наших первичных расчетов было взято значение для ближайшего стабильного соединения $\mathrm{Bi}_{4} \mathrm{Ge}_{3} \mathrm{O}_{12}$ (2:3 $\left.\mathrm{Bi}_{2} \mathrm{O}_{3}-\mathrm{GeO}_{2}\right)$, исследованного в работе [9]. В табл. 1 данное значение выделено курсивом.

Материал тигля - чистая платина. Геометрия изделия соответствует изделию № 100-10 по ГОСТ 6563-75. Масса навески для плавки равна $10 \mathrm{~g}$. Толщина закристаллизовавшегося расплава составляет 1.97-2.4 mm. Теплофизические характеристики материала тигля (чистой платины) были взяты из работы [10].

Моделирование проводилось с использованием профессионального программного комплекса ProCAST. Pacчеты повторяют девять режимов охлаждения, представленных в работе [6] (рис. 1). Отличием от указанной работы являлось только то, что охлаждение с печью велось с контролируемой скоростью $\left(4^{\circ} \mathrm{C} / \mathrm{min}\right)$ с целью сравнения расчетных и реальных скоростей кристаллизации в максимально равновесных условиях. Параметры моделирования тепловой задачи были следующими: температура окружающей среды $20^{\circ} \mathrm{C}$, температура воды $15^{\circ} \mathrm{C}$, температура ликвидуса платины $1768^{\circ} \mathrm{C}$. Коэффициент теплопередачи в случае 

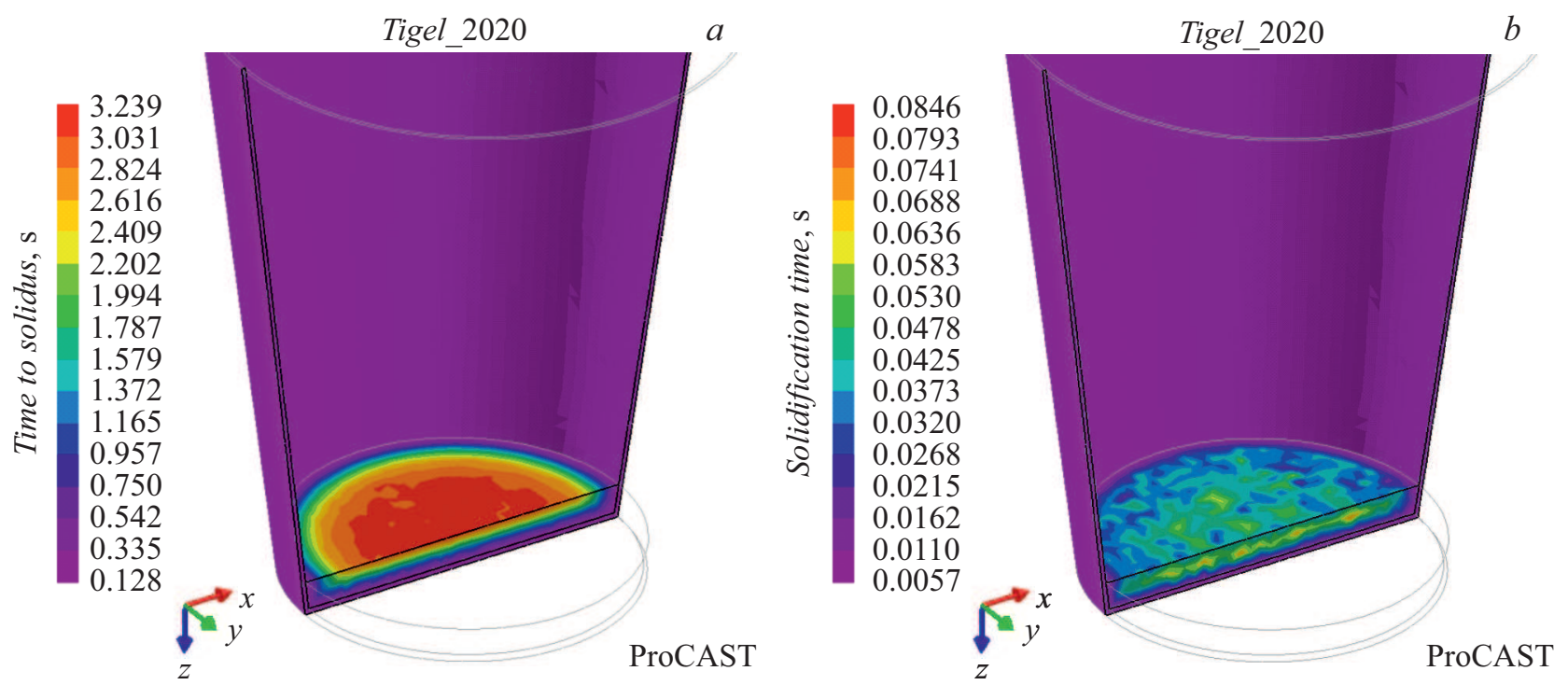

Рис. 2. Распределение времени охлаждения по сечению образца (расплава) в тигле при закалке из зоны $C\left(t_{s t . c o o l .}=1160^{\circ} \mathrm{C}\right) . a-$ охлаждение до полной кристаллизации, $b$ - охлаждение от температуры ликвидуса до температуры солидуса сплава.

расплав-тигель $10000 \mathrm{~W} /\left(\mathrm{m}^{2} \cdot \mathrm{K}\right)$, в случае тигель-вода $5000 \mathrm{~W} /\left(\mathrm{m}^{2} \cdot \mathrm{K}\right)$, в случае тигель-шамотный кирпич $300 \mathrm{~W} /\left(\mathrm{m}^{2} \cdot \mathrm{K}\right)$.

Значения теплофизических характеристик (теплоемкости $C_{p}$, плотности $\rho$ и теплопроводности $\left.\lambda\right) \mathrm{Bi}_{2} \mathrm{GeO}_{5}$ в зависимости от температуры сведены в табл. 1. Полужирным шрифтом выделены значения, полученные с помощью математического прогнозирования, курсивом - значение теплопроводности расплава, взятого от ближайшего стабильного соединения $\mathrm{Bi}_{4} \mathrm{Ge}_{3} \mathrm{O}_{12}$ (2:3 $\left.\mathrm{Bi}_{2} \mathrm{O}_{3}-\mathrm{GeO}_{2}\right)$, исследованного в работе [9].

По результатам моделирования на рис. 2, $a$ приведен пример распределения времени охлаждения по сечению материала в тигле при закалке расплава в тигле в воду из зоны $C$ (режим 3 на рис. $1, a$ ). Аналогичное распределение при охлаждении расплава от ликвидуса до солидуса показано на рис. $2, b$.

Зависимости температуры от времени при охлаждении расплава до комнатной температуры в режимах, представленных на рис. 1, приведены в табл. 2 и в качестве примера закалки на рис. 3. Из данных расчетов видно, что при закалке в воду (рис. 3) скорость охлаждения расплава в центральной части тигля и на расстоянии $0.5 R(R-$ радиус модели, имитирующей объем охлаждаемого расплава, от центра тигля до внутренней стенки тигля) практически одинакова и отличается только на периферии - у стенок тигля и дна, где происходит наиболее быстрый теплоотвод. На этот факт также будут оказывать влияние количество расплава и геометрия самого тигля. При охлаждении на воздухе от температуры начала охлаждения до полного охлаждения скорость охлаждения расплава по сечению в тигле будет различаться меньше, чем при закалке в воду. В случае же охлаждения с печью материал будет иметь минимальный градиент температур между

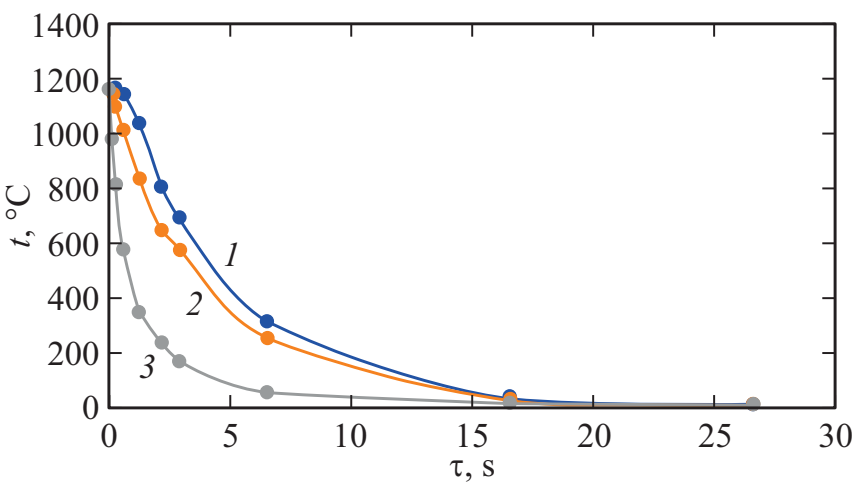

Рис. 3. Зависимость температуры от времени при закалке из зоны $C\left(t_{\text {st.cool. }}=1160^{\circ} \mathrm{C}\right)$ в центральной части тигля $(1)$, на расстоянии $0.5 R(2)$ и $0.9 R(3)$.

слоями. Из табл. 2 видно, что полученные расчетные значения как для времени кристаллизации, так и для полного охлаждения хорошо коррелируют между собой и не имеют грубых и явно заметных выпадов.

Сопоставление расчетного времени охлаждения с практическими результатами (табл. 2) еще раз подтверждает наши выводы и показывает хорошую сходимость теоретического моделирования с практическими результатами.

Таким образом, показана возможность моделирования процессов охлаждения метастабильного соединения $\mathrm{Bi}_{2} \mathrm{GeO}_{5}$ с кристаллической структурой типа Ауривиллиуса при помощи программного комплекса ProCAST. Результаты моделирования показывают хорошую сходимость расчетных значений с реальными скоростями охлаждения расплавов. Данный способ расчетов в программном комплексе ProCAST может быть пригоден для моделирования процессов нагрева и охлаждения мета- 
Таблица 2. Время кристаллизации и полного охлаждения расплава состава $1: 1 \mathrm{Bi}_{2} \mathrm{O}_{3}-\mathrm{GeO}_{2}$ при охлаждении его от различных температур начала охлаждения и в различных режимах, полученное с помощью математического моделирования в программном комплексе ProCAST (сравнение расчетного и реального времени кристаллизации расплава)

\begin{tabular}{|c|c|c|c|c|c|}
\hline \multirow[b]{2}{*}{$\begin{array}{c}t_{\text {st.cool. }}, \\
C^{\circ}\end{array}$} & \multirow[b]{2}{*}{$\begin{array}{c}\text { Способ } \\
\text { охлаждения } \\
\text { тигля } \\
\text { с расплавом }\end{array}$} & \multirow[b]{2}{*}{$\begin{array}{c}\text { Расчетное время } \\
\text { кристаллизации, } \\
\text { s } \\
\text { (значения } \\
\text { округлены } \\
\text { до целых) }\end{array}$} & \multirow[b]{2}{*}{$\begin{array}{c}\text { Реальное } \\
\text { (практическое) } \\
\text { время } \\
\text { кристаллизации, } \\
\text { s }\end{array}$} & \multicolumn{2}{|c|}{ Расчет полного охлаждения } \\
\hline & & & & $\begin{array}{c}\text { Температура, }{ }^{\circ} \mathrm{C} \\
\text { (контроль по } \\
\text { центру тигля, } \\
\text { значения } \\
\text { округлены до } \\
\text { целых) }\end{array}$ & $\begin{array}{c}\text { Время, s } \\
\text { (значения } \\
\text { округлены } \\
\text { до целых) }\end{array}$ \\
\hline \multirow{3}{*}{1160} & $\begin{array}{c}\text { Закалка в } \\
\text { воду }\end{array}$ & 3 & $5-8$ & 36 & 17 \\
\hline & $\begin{array}{c}\text { Охлаждение } \\
\text { на воздухе }\end{array}$ & 17 & 24 & 36 & 392 \\
\hline & $\begin{array}{c}\text { Охлаждение } \\
\text { с печью }\end{array}$ & 5115 & 5100 & 360 & 12011 \\
\hline \multirow{3}{*}{1102} & $\begin{array}{c}\text { Закалка в } \\
\text { воду }\end{array}$ & 3 & & 38 & 16 \\
\hline & $\begin{array}{c}\text { Охлаждение } \\
\text { на воздухе }\end{array}$ & 13 & & 38 & 356 \\
\hline & $\begin{array}{c}\text { Охлаждение } \\
\text { с печью }\end{array}$ & 3368 & & 360 & 11141 \\
\hline \multirow{3}{*}{1037} & $\begin{array}{c}\text { Закалка в } \\
\text { воду }\end{array}$ & 2 & & 56 & 14 \\
\hline & $\begin{array}{c}\text { Охлаждение } \\
\text { на воздухе }\end{array}$ & 10 & & 57 & 236 \\
\hline & $\begin{array}{c}\text { Охлаждение } \\
\text { с печью }\end{array}$ & 2394 & & 360 & 10171 \\
\hline
\end{tabular}

стабильных соединений в системе $\mathrm{Bi}_{2} \mathrm{O}_{3}-\mathrm{GeO}_{2}$ с целью получения их с заранее заданным комплексом свойств и характером микроструктуры, что имеет важное научное и практическое значение.

\section{Благодарности}

Использовано оборудование Красноярского краевого научно-исследовательского центра Федерального исследовательского центра „Красноярский научный центр СО $\mathrm{PAH}^{\prime \prime}$.

\section{Финансирование работы}

Работа выполнена в рамках государственного задания Министерства науки и высшего образования РФ (код научной темы ФСР3-2020-0013).

\section{Конфликт интересов}

Авторы заявляют, что у них нет конфликта интересов.

\section{Список литературы}

[1] И.В. Тананаев, В.М. Скориков, Ю.Ф. Каргин, В.П. Жереб, Изв. АН СССР. Неорган. материалы, 14 (11), 2024 (1978).
[2] В.П. Жереб, Ю.Ф. Каргин, В.М. Скориков, Изв. АН СССР. Неорган. материалы, 14 (11), 2029 (1978).

[3] V.P. Zhereb, V.M. Skorikov, Inorg. Mater., 39 (2), S121 (2003). https://doi.org/10.1023/B:INMA.0000008890.41755.90

[4] В.П. Жереб, Метастабильные состояния в оксидных висмутсодержаших системах (МАКС Пресс, М., 2003).

[5] G. Corsmit, M.A. Van Driel, R.J. Elsenaar, W. Van De Guchte, A.M. Hoogenboom, J.C. Sens, J. Cryst. Growth., 75 (3), 551 (1986).

[6] В.П. Жереб, Т.В. Бермешев, Ю.Ф. Каргин, Е.В. Мазурова, В.М. Денисов, Неорган. материалы, 55 (7), 782 (2019). DOI: $10.1134 / \mathrm{S} 0002337 \mathrm{X} 19060162$ [Пер. версия: 10.1134/S0020168519060165].

[7] В.П. Жереб, Физико-химические исследования метастабильных равновесий в системах $\mathrm{Bi}_{2} \mathrm{O}_{3}-Э \mathrm{O}_{2}$, где Э - Si, Ge, Ti, автореф. канд. дис. (Институт общей и неорганической химии им. Н.С. Курнакова, М., 1980).

[8] Л.Т. Денисова, Н.В. Белоусова, Н.А. Галиахметова, В.М. Денисов, В.П. Жереб, ФТТ, 59 (8), 1659 (2017). DOI: $10.21883 /$ FTT.2017.08.44773.41 [Пер. версия: 10.1134/S106378341708008X].

[9] V.D. Golyshev, M.A. Gonik, V.B. Tsvetovsky, High Temp.-High Press., 35/36 (2), 139 (2003/2004). DOI: $10.1068 / \mathrm{htj} 106$

[10] В.Е. Зиновьев, Теплофизические свойства металлов при высоких температурах. Справочник (Металлургия, М., 1989). 